\section{Breeding discontent}

David Pearce

The Plutonium Business and the Spread of the Bomb.

By Walter C. Patterson.

Paladin: 1984. Pp.272. Pbk f2.95.

THERE are, says Walter Patterson, "nuclear people", "plutonium people" and "fast breeder people". Nuclear people believe in the civilian use of nuclear power for electricity. Plutonium people and fast breeder people believe in the original nuclear dream: the widespread use of plutonium - a by-product of burning uranium fuel - as a fuel for fast reactors which can breed more plutonium. Nuclear people need not be plutonium people but they share the same vision, that of a resource with enormous potential. If the resource is there they cannot understand why it should not be used. Yet resource use has costs as well as benefits; nothing comes free.

Patterson sets out to chart one of the costs of plutonium. The civilian nuclear power dream cannot be distinguished from plutonium as a weapons material, despite all the protestations by plutonium people to the contrary. This he does most successfully in an historical overview from Seaborg's identification of plutonium, through the Manhattan Project, to today's aggressive fast breeder programme in France and the limited triumphs and many failures elsewhere. The Super-Phénix is nearing completion in France at a cost of some $\$ 10,000$ million. It is jointly owned by France, Italy, Germany, Britain, the Netherlands and Belgium. Patterson is quite clear how such a staggering cost is justified by advocates of the programme it will provide military plutonium when other supplies have gone. We are all, it seems, helping to finance French nuclear weapons.

Patterson sees no hope in existing safeguards against the spread of military plutonium from civilian sources, whether in the International Atomic Energy Authority or the Non-Proliferation Treaty, the subject of so many ambiguous and confusing interpretations. For the truth is that no one knows collectively how much plutonium exists. One "best guess" for 1982 suggests some 175 tonnes of plutonium "in stock" in civilian sources in the non-communist world (though this appears not to account for high-purity plutonium from Magnox reactors which, if evidence to the Sizewell Inquiry is correct, actually has been diverted to US nuclear weapons). The annual production rate of plutonium is about 40 tonnes. The prospect of control thus seems remote.

In the same light it is easy to see why plutonium people are not concerned about the niceties of nuclear power economics. Any breeder reactor should be credited with the "value" of the plutonium it produces. By the same token, in the absence of a large breeder programme, all conventional nuclear power stations should be credited with the value of the plutonium in their spent fuel. That value lies in the benefit to world security from having nuclear weapons, a value many will find difficult to believe is less than a very large minus number indeed. But if this is the "real" economics of nuclear power why don't plutonium people admit it? The majority may not dispute the positive value of nuclear weapons. The answer may be that most plutonium people, just like most people, do not know the connection between civilian and military plutonium.

The alternative is that they do know the link but cannot see how stopping the civilian programme would help. After all, the weapons programme began with reactors dedicated to military plutonium. Electricity was incidental. Patterson offers no guidance on this point. For him it is enough that plutonium production is already out of control. With only a short time to go to the fortieth anniversary of Nagasaki we can only contemplate whether the lapse of time is the truest testament to man's ability to control his fearsome drive to selfdestruction, or just an interlude between appalling but vastly different events.

David Pearce is Professor of Economics at University College London.

\section{Talk of Kyoto}

\section{F.S. Rosen.}

\section{Progress in Immunology $\mathbf{V}$.}

Edited by Y. Yamamura and T. Tada Academic: 1984. Pp.1,640. \$110, 185 .

IN August, Kyoto is inhospitably hot. Certainly Baedeker, if he ever had reached there, would have found it situated in an unhealthy valley, nonetheless worthy of being reached in slow stages from Edo by the great Tokaido so beautifully depicted in the wood-block prints of Hokusai and Hiroshige. Instead, in August 1983, some 4,000 immunologists were disgorged in haste from the bullet trains, arriving with frequent and clockwork regularity from Osaka and Tokyo, for their triennial selfcongratulatory pow-wow.

Over 150 dense, compact summaries of all the symposium lectures have been published in this thick volume. It is a timely and state-of-the art overview of the whole field of immunology, in just over 1,600 pages of well-set, readable print. To read it from cover to cover is mind boggling, but certainly very informative. Summaries of the dozens of work-shops which took place during the congress are not included but that does not detract from the book; it might have resulted in overkill. Anthony Watkinson recently pointed out (Nature 312,201 ; 1984) that "the transformation of a transient three or four days of academic exchange into an enduring collection of reviews can be an invaluable contribution to learning"'. Progress in Immunology V measures up to just that.

On the fourth afternoon of the meeting, a spontaneously exuberant moment occurred when it became apparent that the $T$ cell receptor had at long last been identified in Denver and Boston, in California and Texas. It was one of those rare times when an international congress is ignited by the tinder of a major discovery. Unfortunately, not all of the presentations at that session have been included. While dwelling on the omissions from this volume, it should be noted that there was almost nothing in the congress on immunodeficiency at a time when, among other things, AIDS is creating a stir and yielding information on lymphocytotropic retroviruses. There is also an omission of neuroimmunology at a time when immunology has provided interesting probes for the neurobiologist. And there is barely a nod in the direction of transplantation biology despite some good summaries of the current status of work on the major histocompatibility locus in mouse and man. Maybe all this will be fixed next time around.

Immunologists are returning to their roots with some highly productive and heuristic results. The articles by B.B. Bloom on leprosy, A. Capron on schistosomes and the Nussenzweigs on malaria are vivid demonstrations of how useful immunology can still be to its parent science. The emergence of synthetic vaccines also promises to burgeon into something usefully applicable, and current work in Israel and France on this subject is also well summarized.

The best subject coverage in the book concerns the molecular biology of the immunoglobulin and major histocompatibility genes. This field has moved very rapidly as can be gleaned from the outstanding summaries by D. Baltimore, L. Hood, T. Honjo and others. In contrast there are the still muddy fields of lymphokines, growth factor and other humors. They are desperately in need of being set right.

The high specific gravity of this tome is occasionally relieved by inspirational words, by D.W. Talmage, N.A. Mitchison and R.A. Good, that set the field in perspective. The opening reflections of $B$. Benacerraf epitomize the message of this meeting: "Nature rewards and yields its magic secrets to the most daringly imaginative. Hard work and dedication, while essential, are not enough". Time will tell if this challenge is to be met at the next congress in Toronto in 1986, and if that meeting too produces such a profusion of progress and excitement.

F.S. Rosen is James L. Gamble Professor of Pediatrics at Harvard Medical School, and Head of the Immunology Division at the Children's Hospital, Boston. 